\title{
To assess the brand preference in hybrid cotton seeds in North Karnataka
}

\author{
Srividyarani S. Sajjan and N. M. Kerur
}

Received : 28.01.2018; Revised : 12.03.2018; Accepted : 26.03.2018

\begin{abstract}
Cotton often referred as "White gold" or the "King of fibres" enjoys a predominant position amongst all cash crops in India and is closely linked to human civilization itself. Haveri and Dharwad districts were selected for the study from each district 60 farmers were selected. Among the ten factors considered for the study of Brand preference, in Dharwad and Haveri first preference given to High yield compared to other brand is the important and major factor where with the mean score (77.6) and (79.6) of the farmers considered this factor before they go for purchasing the seeds and least preference was given to price is less with mean score (28.3) and (25.2). The hybrid cotton seeds tends to be less popular in Dharwad district (265 kg) compared to Haveri district $(318.5 \mathrm{~kg}$ ). Kanaka brand was more popular among the different brands in both the districts, which was to the extent of 50 per cent followed by super star, Pratap and Rasi. The 50 per cent of the farmers prefer kanaka variety because important characteristics of Kanaka hybrid such as big size of boles, more number of boles per plant, higher yield and resistant to bollworms as compared to other hybrids etc.
\end{abstract}

KEY WORDS : : Hybrid cotton seeds, Brand preference, Brand loyalty

How to cite this paper : Sajjan, Srividyarani S. and Kerur, N.M. (2018). To assess the brand preference in hybrid cotton seeds in North Karnataka. Internat. J. Com. \& Bus. Manage, 11(1) : 75-80, DOI: 10.15740/HAS/IJCBM/11.1/75-80. 